\title{
Early DNR Order and Long-Term Prognosis Among Patients Hospitalized for Acute Heart Failure: Single-Center Cohort Study in Japan
}

This article was published in the following Dove Press journal: International Journal of General Medicine

\author{
Eiji Hiraoka' \\ Junya Arai \\ Shunsuke Kojima $\mathbb{D D}^{\prime}$ \\ Yasuhiro Norisue ${ }^{2}$ \\ Toshihiko Suzuki ${ }^{3}$ \\ Yosuke Homma (iD) \\ Osamu Takahashi ${ }^{5}$ \\ Kotaro Obunai ${ }^{6}$ \\ Hiroyuki Watanabe ${ }^{6}$ \\ 'Department of Internal Medicine, Tokyo \\ Bay Urayasu Ichikawa Medical Center, \\ Urayasu-city, Chiba 279-000I, Japan; \\ ${ }^{2}$ Department of Critical Care and \\ Pulmonary Medicine, Tokyo Bay Urayasu \\ Ichikawa Medical Center, Urayasu-city, \\ Chiba 279-000I, Japan; ${ }^{3}$ Department of \\ Nephrology, Endocrinology, and \\ Diabetes, Tokyo Bay Urayasu Ichikawa \\ Medical Center, Urayasu-city, Chiba 279- \\ 000I, Japan; ${ }^{4}$ Department of Emergency \\ Medicine, Tokyo Bay Urayasu Ichikawa \\ Medical Center, Urayasu-city, Chiba 279- \\ $000 \mathrm{I}$, Japan; ${ }^{5}$ Department of Internal \\ Medicine, St Luke's International \\ Hospital, Chuo-ku, Tokyo 104-8560, \\ Japan; ${ }^{6}$ Department of Cardiology, Tokyo \\ Bay Urayasu Ichikawa Medical Center, \\ Urayasu-city, Chiba 279-000I, Japan
}

Correspondence: Eiji Hiraoka

Department of Internal Medicine, Tokyo Bay Urayasu Ichikawa Medical Center,

3-4-32, Todaijima, Urayasu-city, Chiba

279-000I, Japan

Tel +8I-47-35I-3I0I

Fax +8I-47-35I2-6237

Email eijih@jadecom.jp
Purpose: An early do-not-resuscitate (DNR) order is classified as such when it occurs within 24 hours of admission. Early DNR has been previously associated with in-hospital mortality among acute heart failure (AHF) patients and one-year mortality among patients discharged from ICU. Here, we investigate whether early DNR is associated with long-term mortality in AHF Japanese patients, by performing a retrospective cohort study.

Patients and Methods: We retrospectively investigated all patients with AHF, admitted to our hospital between April 2013 and March 2015, and survived to discharge. We obtained data on demographics, comorbidities, laboratory and echocardiography results, social background, DNR status, and outcomes (one-year death). The association of early DNR with oneyear death was analyzed by multivariate logistic regression analysis.

Results: Among 370 survive to discharge patients, 48 (12\%) were lost to follow up. We analyzed 322 patients. The median age was 74 years, and $80(25 \%)$ had an early DNR order. Patients with a DNR order were older and displayed more activities of daily living (ADL)dependence. Early DNR was associated with higher one-year mortality.

Conclusion: Early DNR was associated with one-year mortality among AHF patients. Further studies are necessary to investigate unmeasured factors associated with a worse prognosis related to early DNR among AHF patients.

Keywords: acute heart failure, early DNR, prognosis, end of life, advance care planning

\section{Introduction}

The discussion on whether resuscitation should take place or not in case of cardiopulmonary arrest can be started prior to or on admission. Do-not-resuscitate (DNR) orders allow patients to forgo CPR in the event of cardiac arrest ${ }^{1}$ and can be classified as either early or late: early, if the DNR order is given within 1 day after admission or late, if given at a later time point during hospitalization. ${ }^{2,3}$ Factors associated with early DNR orders include the patients' pre-hospital frailty, the burden of comorbidities, and goal of care. ${ }^{2}$ Late DNRs can occur for reasons such as lack of response to therapy or because a serious disease is diagnosed. Therefore, a late DNR order is often a marker of the severity of the patients' illness. $^{3}$

Importantly, DNRs cannot be applied to any situation other than cardiac arrest. The guidelines published by the American Medical Association's Council on Ethical and Judicial Affairs state that "DNR orders only preclude resuscitative efforts and should not influence other therapeutic interventions that may be appropriate." ${ }^{, 4}$ Nonetheless, 
DNR orders have been applied to procedures that include evidence-based life-prolonging treatments other than CPR for cardiac arrest. Indeed, patients in the USA admitted for acute heart failure (AHF) were less likely to undergo an assessment of their left ventricular function, receive treatment with angiotensin-converting enzyme inhibitors or angiotensin II receptor blockers (ARB), or undergo counseling about lifestyle modifications if they had a DNR order. ${ }^{5}$ Accordingly, an early DNR was previously associated with increased in-hospital mortality among AHF patients. ${ }^{6}$ Its association with one-year mortality has not been investigated yet.

The worse prognosis associated with early DNRs might be explained by a worse quality of care (QOC). In our hospital, to prevent misuse of DNR orders, we have developed a specific order sheet for DNR orders (Figure 1) and have lectures about the topic quarterly, to ensure that the proper procedures are followed, both in terms of DNR order implementation and in the treatment of patients with a DNR order. In these conditions, we have previously demonstrated that the presence of a DNR order did not worsen the QOC of heart failure patients. ${ }^{7}$ Even though we did not evaluate the effect of an early DNR on clinical outcomes, patients with an early DNR order had higher inhospital mortality than those without. ${ }^{7}$ In this situation, where the DNR order does not affect the QOC of AHF patients, we analyzed the same cohort to understand whether an early DNR order is a prognostic indicator of the one-year mortality among hospitalized AHF patients.

\section{Subjects and Methods Subjects}

This retrospective, single-center, cohort study included adult patients who were admitted to our hospital with a primary diagnosis of AHF between April 2013 and March 2015, and survived to discharge. The patients were at least 18 years old at the time of hospital admission. An internal medicine specialist reviewed the whole hospital course by chart review, which included chest X-ray, echocardiography data, and response to acute heart failure treatment, and confirmed the diagnosis according to the Framingham criteria. $^{8}$

\section{Setting}

Our hospital is an urban acute care teaching facility, with 344 beds. Patients with AHF are under the care of general internal medicine teams, consisting of 2 to 3 residents, 1 hospitalist attending physician, and a cardiologist. Lectures on advance care planning (ACP) and DNR orders are conducted quarterly, to ensure that the appropriate DNR order-related procedures are followed, as described elsewhere. $^{7}$ To prevent misuse of DNR orders and to ensure the patients' will and preference regarding CPR are respected, we use the code status order sheet shown in Figure 1. The precise discussion of ACP and code status are documented in the patient's progress note.

\section{Data Collection}

The characteristics of the patients were obtained by chart review. The following information was obtained: age, sex, body mass index (BMI), vital signs, major comorbidities (hypertension, chronic obstructive pulmonary disease, malignancy, dementia, chronic kidney disease, hemodialysis, diabetes, dyslipidemia, stroke, and atrial fibrillation), previous cardiac problems and procedures (myocardial infarction, percutaneous coronary intervention (PCI), coronary artery bypass grafting (CABG), valve surgery, cardiac pacemaker, implantable cardioverter defibrillator

\section{Code status order sheet}

In case of cardiopulmonary arrest (with no palpable pulse):

Choose one of below

DNR (proceed to death pronounce)

Full code

In case of emergency event other than cardiopulmonary arrest (with palpable pulse), Choose below and erase if not applicable.

Never intubate in any situation.

Never perform electrical shock in any situation.

Never perform ( ) in any situation.

Figure I Code status order sheet used in our hospital. 
(ICD)/cardiac resynchronization therapy with defibrillator (CRT-D) and hospitalization due to heart failure), social background (dependency in activities of daily living (ADL)), DNR status within 24 hours after admission (presence or absence of an early DNR order), smoking, etiology and exacerbating factors of heart failure, and laboratory results on admission. In terms of DNR, when a DNR order was documented within 24 hours after admission, an early DNR order was adjudicated as present. We also obtained data on clinical outcomes (death within 1 year after discharge) by chart review, mail, and/or telephone calls to patients or their families.

\section{Statistical Analysis}

Continuous variables were expressed as median (interquartile range [IQR]: $25 \%$ and $75 \%$ ), and discrete variables were summarized as percentages. Continuous variables were analyzed and compared using the Mann-Whitney $U$-test, and dichotomous variables were analyzed and compared using the chi-square test. $P$ values $<0.05$ were considered to indicate a statistically significant difference.

To analyze whether an early DNR order is associated with one-year mortality, multivariate logistic regression analysis was performed. To adjust for baseline cohort differences between DNR-group and non-DNR group, we performed a multivariate logistic regression analysis with a forward stepwise method for one-year death after discharge. All variables with $P$ value $<0.1$ in univariate analysis between the DNR group and the non-DNR group were used. Then, the adjusted ORs were determined. Treatment with beta-blockers and ACE inhibitors (ACEi) or ARB are also important prognostic factors for heart failure patients with reduced ejection fraction (EF) and anticoagulation for atrial fibrillation. However, the prescription rate of these medicines was very high in the study population and not statistically different between the DNR and non-DNR group (94\% vs $94 \%, P=1.0$ beta-blocker, $90 \%$ vs $97 \%$, $P=0.47$, for ACEi or ARB, $97 \%$ vs $100 \%, P=1.0$, for anticoagulation) as shown previously, ${ }^{7}$ so we did not include these parameters for the evaluation.

The variance inflation factor (VIF) was used to check for multicollinearity between the factors investigated. All statistical analyses were conducted using IBM SPSS version 22.0 (IBM, Armonk, NY, USA). Patients with missing data were excluded from the analysis. For the analysis of the one-year outcome and the associated factors of death, patients lost to follow-up were excluded.

\section{Informed Consent and Institutional \\ Review Board Approval}

The study protocol was approved by the institutional review board of the Tokyo Bay Urayasu Ichikawa Medical Center. Due to the anonymous nature of the data, the requirement for informed consent for the chart review was waived.

\section{Results \\ Patient Characteristics}

A total of 394 patients admitted to our hospital from April 2013 to March 2015 were diagnosed as having heart failure. Of those, 24 patients died in the hospital. Among the 370 survival to discharge patients (DNR group $97(26 \%)$, non-DNR group $273(74 \%)), 48$ patients (DNR group $17(35 \%)$, non-DNR group $31(65 \%))$ were lost to follow-up after one year (follow-up rate, 88\%). Accordingly, they were excluded from the evaluation of prognostic factors for one-year mortality. Therefore, a total of 322 patients (DNR-group: 80 (25\%) and non-DNR group: $242(75 \%))$ were analyzed to determine the oneyear outcome and the association of early DNR with oneyear mortality (Table 1). Median age was 74. The early DNR patients were more elderly and more likely to have low BMI, dementia, as well as lower Hb level. They were more likely to be ADL-dependent. Considering the high rate of loss to follow-up, we compared characteristics between the lost follow-up group and the complete followup group. The lost follow-up patients were more likely to have dementia (Table 2). Numerically, the rates of early DNR, ADL-dependency, and hemodialysis were higher in the lost follow-up group although the difference was not statistically significant.

\section{Early DNR and One-Year Mortality After Discharge}

The mortality was $13 \%$ (43 out of 322 ) among all patients. The DNR group had higher mortality than the non-DNR group (28.8\% (23 out of 80 ) vs $8.3 \%$ (20 out of 242 ), $P<0.001)$. According to univariate analysis, age $\geq 75$ years, sex, $\mathrm{BMI}<21 \mathrm{~kg} / \mathrm{m}^{2}$, diastolic blood pressure, dementia, ADL dependency, $\mathrm{EF}<40 \%$, serum blood urea nitrogen (BUN), creatinine, sodium, hemoglobin $(\mathrm{Hb})<10 \mathrm{~g} / \mathrm{dL}$, and history of coronary artery disease were chosen for the forward stepwise method for multivariable analysis to investigate whether an early DNR was an associated factor of one-year death. Not only BMI $<21 \mathrm{~kg} / \mathrm{m}^{2}$, ADL- 
Table I Patient Characteristics According to DNR Status

\begin{tabular}{|c|c|c|c|}
\hline & $\begin{array}{l}\text { Absence of DNR } \\
\text { Order }(\mathrm{N}=242)\end{array}$ & $\begin{array}{l}\text { Presence of DNR } \\
\text { Order }(\mathrm{N}=80)\end{array}$ & $P$ value \\
\hline $\begin{array}{l}\text { Demographic } \\
\text { Age (years) } \\
\text { Age } \geq 75 \text { years } \\
\text { Sex, male } \\
\text { BMI }\left(\mathrm{kg} / \mathrm{m}^{2}\right) \\
\text { BMI }<21 \mathrm{~kg} / \mathrm{m}^{2}\end{array}$ & $\begin{array}{l}71(62,78) \\
101(42) \\
152(63) \\
24.2(21.5,27.4) \\
41(17)\end{array}$ & $\begin{array}{l}83(74,89) \\
60(75) \\
31(39) \\
20.8(19.1,24.5) \\
38(48)\end{array}$ & $\begin{array}{l}<0.001 \\
<0.001 \\
<0.001 \\
<0.001 \\
<0.001\end{array}$ \\
\hline $\begin{array}{l}\text { Vital signs } \\
\qquad \mathrm{SBP}(\mathrm{mmHg}) \\
\mathrm{SBP}<100 \mathrm{mmHg} \\
\mathrm{DBP}(\mathrm{mmHg}) \\
\mathrm{HR} \text { (beats/ } \\
\text { minute) }\end{array}$ & $\begin{array}{l}148(129,171) \\
15(6.2) \\
90(74,108) \\
95(78,112)\end{array}$ & $\begin{array}{l}144(120,177) \\
2(2.5) \\
81(64,103) \\
91(76,103)\end{array}$ & $\begin{array}{l}0.72 \\
0.26 \\
0.010 \\
0.087\end{array}$ \\
\hline $\begin{array}{l}\text { Comorbidities } \\
\text { Hypertension } \\
\text { COPD } \\
\text { Malignancy } \\
\text { Dementia } \\
\text { CKD } \\
\text { Hemodialysis } \\
\text { DM } \\
\text { Stroke } \\
\text { Atrial fibrillation }\end{array}$ & $\begin{array}{l}144(60) \\
11(4.5) \\
16(6.6) \\
19(7.9) \\
36(15) \\
15(6.2) \\
77(32) \\
28(12) \\
69(29)\end{array}$ & $\begin{array}{l}54(68) \\
3(3.8) \\
7(8.8) \\
31(39) \\
18(23) \\
5(6.3) \\
24(30) \\
10(13) \\
23(29)\end{array}$ & $\begin{array}{l}0.13 \\
0.57 \\
0.62 \\
<0.001 \\
0.12 \\
1.0 \\
0.78 \\
0.84 \\
1.0\end{array}$ \\
\hline $\begin{array}{l}\text { Cardiac history } \\
\text { Myocardial } \\
\text { infarction } \\
\text { PCI } \\
\text { CABG } \\
\text { Valve surgery } \\
\text { Pace maker } \\
\text { ICD or CRT-D } \\
\text { History of AHF } \\
\text { hospitalization }\end{array}$ & $\begin{array}{l}2(0.8) \\
27(11) \\
14(5.8) \\
8(3.3) \\
6(2.5) \\
4(1.7) \\
64(26)\end{array}$ & $\begin{array}{l}1(1.2) \\
7(8.8) \\
4(5.0) \\
4(5.0) \\
2(2.5) \\
3(3.8) \\
25(31)\end{array}$ & $\begin{array}{l}0.9 \\
0.68 \\
\\
1.0 \\
0.50 \\
1.0 \\
0.37 \\
\\
0.47\end{array}$ \\
\hline $\begin{array}{l}\text { Social history } \\
\text { ADL- } \\
\text { dependence }\end{array}$ & $33(14)$ & $33(4 I)$ & $<0.001$ \\
\hline $\begin{array}{l}\text { Etiology } \\
\text { Hypertensive } \\
\text { heart failure } \\
\text { Coronary } \\
\text { artery disease } \\
\text { ACS } \\
\text { Valvular heart } \\
\text { disease }\end{array}$ & $\begin{array}{l}78(32) \\
77(32) \\
42(16) \\
37(15)\end{array}$ & $\begin{array}{l}32(40) \\
17(21) \\
4(5.0) \\
10(12.5)\end{array}$ & $\begin{array}{l}0.22 \\
0.088 \\
0.012 \\
0.59\end{array}$ \\
\hline $\begin{array}{l}\text { Echocardiography } \\
\text { EF }<40 \% \\
\text { EF } 40-50 \% \\
\text { EF }>50 \%\end{array}$ & $\begin{array}{l}119(49) \\
37(15) \\
86(36)\end{array}$ & $\begin{array}{l}30(38) \\
17(22) \\
33(41)\end{array}$ & $\begin{array}{l}0.092 \\
0.226 \\
0.423\end{array}$ \\
\hline $\begin{array}{l}\text { Laboratory data } \\
\text { BUN (mg/dL) }\end{array}$ & $19.5(14.4,29.9)$ & $25.6(19.0,35.9)$ & $<0.001$ \\
\hline
\end{tabular}

(Continued)
Table I (Continued).

\begin{tabular}{|l|l|l|l|}
\hline & $\begin{array}{l}\text { Absence of DNR } \\
\text { Order }(\mathbf{N}=\mathbf{2 4 2})\end{array}$ & $\begin{array}{l}\text { Presence of DNR } \\
\text { Order }(\mathbf{N}=80)\end{array}$ & P value \\
\hline $\mathrm{BUN}>43 \mathrm{mg} / \mathrm{dL}$ & $30(12)$ & $13(16)$ & 0.45 \\
$\mathrm{Cr}(\mathrm{mg} / \mathrm{dL})$ & $0.93(0.75,1.42)$ & $1.0(0.78,2.0)$ & 0.057 \\
$\mathrm{Cr}>1.5 \mathrm{mg} / \mathrm{dL}$ & $56(23)$ & $24(30)$ & 0.18 \\
$\mathrm{Na}(\mathrm{mEq} / \mathrm{L})$ & $139(136,14 \mathrm{I})$ & $139(135,141)$ & 0.204 \\
$\mathrm{Na}<135 \mathrm{mEq} / \mathrm{L}$ & $28(12)$ & $14(18)$ & 0.02 \\
$\mathrm{Hb}(\mathrm{g} / \mathrm{dL})$ & $12.9(10.9,14.4)$ & $10.8(9.6,12.5)$ & $<0.001$ \\
$\mathrm{Hb}<10 \mathrm{~g} / \mathrm{dL}$ & $32(13)$ & $29(36)$ & $<0.001$ \\
$\mathrm{BNP}(\mathrm{pg} / \mathrm{mL})$ & $677(280,1767)$ & $678(347,1485)$ & 0.886 \\
\hline
\end{tabular}

Notes: Values are presented as median (25\%, $75 \%$ interquartile range) or $\mathrm{N}(\%)$; BMI data was missing in 2 patients (Non-DNR patient). BNP data was missing in 58 (24\%) DNR patients and 14 (18\%) non-DNR patients.

Abbreviations: DNR, do-not-resuscitate order; BMI, body mass index; SBP, systolic blood pressure; DBP, diastolic blood pressure; HR, heart rate; COPD, chronic obstructive pulmonary disease; CKD, chronic kidney disease; DM, diabetes mellitus; $\mathrm{PCl}$, percutaneous coronary intervention; CABG, coronary artery bypass graft; $I C D$, implantable cardioverter defibrillator; CRT-D, cardiac resynchronization therapy with defibrillator; AHF, acute heart failure; ADL, activities of daily living; ACS, acute coronary syndrome; $\mathrm{EF}$, ejection fraction; $\mathrm{BUN}$, blood urea nitrogen; $\mathrm{Cr}$, creatinine; $\mathrm{Na}$, sodium; $\mathrm{Hb}$, hemoglobin; BNP, B-type natriuretic peptide.

dependency, and $\mathrm{Hb}<10 \mathrm{~g} / \mathrm{dL}$ but also an early DNR were associated with one-year death (Table 3). All the VIF values were less than 1.3 , demonstrating that there was no collinearity between the factors. Of note, among 242 non-early DNR patients, late DNR was ordered for 22 patients during the index hospitalization.

\section{Discussion}

In this study, $25 \%$ of patients had an early DNR order among acute heart failure patients. Patients with early DNR orders were older and were more likely to be women than those without early DNR orders. They were also more likely to be ADL-dependent. Our study is the first to demonstrate that it is associated with one-year mortality. As much as $12 \%$ of patients were excluded from the investigation because of lost follow-up. In comparison with the complete follow-up group, they were more likely to be demented.

Having an early DNR order was associated with one-year mortality among acute heart failure patients. This could be explained by the mere existence of a DNR order influencing decisions taken by physicians, including those pertaining to non-CPR procedures. This is despite that, in theory, this should not be the case, unless a special order related to each non-CPR procedure is made. ${ }^{9,10}$ It is possible that physicians mistake a DNR order with a comfort care order. Indeed, one study demonstrated that $64 \%$ of physicians in the USA equated DNR orders with comfort care/end of life care rather than full care. ${ }^{11}$ It is also possible that, even though 
Table 2 Patient Characteristics According to Follow-Up Status

\begin{tabular}{|c|c|c|c|c|}
\hline & $\begin{array}{l}\text { All } \\
N=370\end{array}$ & $\begin{array}{l}\text { Lost Follow-Up } \\
N=48\end{array}$ & $\begin{array}{l}\text { Complete Follow- } \\
\text { Up } \\
N=322\end{array}$ & $P$ value \\
\hline Early DNR status & $97(26)$ & $17(35)$ & $80(25)$ & 0.158 \\
\hline \multicolumn{5}{|l|}{ Demographic } \\
\hline Age (years) & $75(65,83)$ & $79(69,83)$ & $74(65,83)$ & 0.199 \\
\hline Age $\geq 75$ years & $178(48)$ & $17(35)$ & $16 \mid(50)$ & 0.077 \\
\hline Sex, male & $208(56)$ & $25(52)$ & I83 (57) & 0.535 \\
\hline BMI $\left(\mathrm{kg} / \mathrm{m}^{2}\right)$ & $23(2 \mid, 26)$ & $22.4(20.0,24.8)$ & $23.7(19.1,26.4)$ & 0.156 \\
\hline $\mathrm{BMI}<2 \mathrm{l} \mathrm{kg} / \mathrm{m}^{2}$ & $97(26)$ & $18(38)$ & $79(25)$ & 0.077 \\
\hline Presence of early DNR & $97(26)$ & $17(35)$ & $80(25)$ & 0.158 \\
\hline \multicolumn{5}{|l|}{ Vital signs } \\
\hline $\mathrm{SBP}(\mathrm{mmHg})$ & $148(\mid 28,174)$ & $163(129,181)$ & I $48(|28| 7 \mid)$, & 0.118 \\
\hline $\mathrm{SBP}<100 \mathrm{mmHg}$ & $19(5.1)$ & $2(4.2)$ & $17(5.3)$ & 1.0 \\
\hline $\mathrm{DBP}(\mathrm{mmHg})$ & $89(71,108)$ & $90(74,108)$ & $81(64,103)$ & 0.153 \\
\hline HR (beats/minute) & $93(77,112)$ & $94(73,116)$ & $93(78,111)$ & 0.893 \\
\hline \multicolumn{5}{|l|}{ Comorbidities } \\
\hline Hypertension & $225(6 I)$ & $27(56)$ & $198(62)$ & 0.53 \\
\hline COPD & $15(4.1)$ & $I(2.1)$ & $14(4.3)$ & 0.70 \\
\hline Malignancy & $26(7.0)$ & $3(6.3)$ & $23(7.1)$ & 1.0 \\
\hline Dementia & $66(18)$ & $16(33)$ & $50(16)$ & 0.018 \\
\hline CKD & $65(18)$ & II (23) & $54(17)$ & 0.31 \\
\hline Hemodialysis & $27(7.0)$ & $7(15)$ & $20(6.2)$ & 0.066 \\
\hline DM & $123(31)$ & $12(25)$ & $10 \mid(31)$ & 0.41 \\
\hline Stroke & $46(12)$ & $8(17)$ & $38(12)$ & 0.35 \\
\hline Atrial fibrillation & $106(29)$ & $14(29)$ & $92(29)$ & 1.0 \\
\hline \multicolumn{5}{|l|}{ Cardiac history } \\
\hline Myocardial infarction & $42(\mathrm{II})$ & $8(17)$ & $34(11)$ & 0.22 \\
\hline $\mathrm{PCl}$ & $24(6.4)$ & $6(13)$ & $18(5.6)$ & 0.11 \\
\hline CABG & $15(4.0)$ & $3(6.3)$ & $12(3.7)$ & 0.43 \\
\hline Valve surgery & $9(2.4)$ & $I(2.1)$ & $8(2.5)$ & 1.0 \\
\hline Pace maker & II (3.0) & $4(8.3)$ & $7(2.2)$ & 0.041 \\
\hline ICD/CRT-D & $3(0.8)$ & $0(0)$ & $3(0.9)$ & 1.0 \\
\hline History of AHF hospitalization & $130(35)$ & $22(48)$ & $108(35)$ & 0.11 \\
\hline \multicolumn{5}{|l|}{ Social history } \\
\hline ADL-dependence & $81(22)$ & $15(31)$ & $66(2 I)$ & 0.096 \\
\hline \multicolumn{5}{|l|}{ Etiology } \\
\hline Hypertensive heart failure & $132(36)$ & $22(46)$ & $110(34)$ & 0.15 \\
\hline Coronary artery disease & $110(30)$ & $16(33)$ & $94(29)$ & 0.088 \\
\hline ACS & $47(13)$ & $5(10)$ & $42(13)$ & 0.81 \\
\hline Valvular heart disease & $59(16)$ & $12(25)$ & $47(15)$ & 0.088 \\
\hline \multicolumn{5}{|l|}{ Echocardiography } \\
\hline$E F<40 \%$ & $|7|(46)$ & $22(46)$ & $149(46)$ & 1.0 \\
\hline EF $40-50 \%$ & $62(17)$ & $8(17)$ & $54(17)$ & 1.0 \\
\hline $\mathrm{EF}>50 \%$ & $137(37)$ & $18(37)$ & $119(37)$ & 1.0 \\
\hline \multicolumn{5}{|l|}{ Laboratory data } \\
\hline BUN (mg/dL) & $21.5(\mid 5.6,31.8)$ & $22.1(15.3,34.3)$ & $22.0(15.6,31.5)$ & 0.893 \\
\hline
\end{tabular}

(Continued) 
Table 2 (Continued).

\begin{tabular}{|c|c|c|c|c|}
\hline & $\begin{array}{l}\text { All } \\
N=370\end{array}$ & $\begin{array}{l}\text { Lost Follow-Up } \\
N=48\end{array}$ & $\begin{array}{l}\text { Complete Follow- } \\
\text { Up } \\
\mathrm{N}=322\end{array}$ & $P$ value \\
\hline $\mathrm{BUN}>43 \mathrm{mg} / \mathrm{dL}$ & $52(14)$ & $9(19)$ & $43(13)$ & 0.37 \\
\hline $\mathrm{Cr}(\mathrm{mg} / \mathrm{dL})$ & $0.95(0.75,1.5)$ & I.I (0.7I, I.8) & $0.95(0.75,1.5)$ & 0.427 \\
\hline $\mathrm{Cr}>1.5 \mathrm{mg} / \mathrm{dL}$ & $94(25)$ & $14(29)$ & $80(25)$ & 0.59 \\
\hline $\mathrm{Na}(\mathrm{mEq} / \mathrm{L})$ & $139(136,141)$ & $139(|35| 4 \mid)$, & $139(136,14 \mid)$ & 0.926 \\
\hline $\mathrm{Na}<135 \mathrm{mEq} / \mathrm{L}$ & $53(14)$ & II (29) & $42(13)$ & 0.02 \\
\hline $\mathrm{Hb}(\mathrm{g} / \mathrm{dL})$ & $12.2(10.5,13.8)$ & $11.8(10.9,13.6)$ & $12.3(10.5,14.0)$ & 0.226 \\
\hline $\mathrm{Hb}<10 \mathrm{~g} / \mathrm{dL}$ & $68(18)$ & $7(15)$ & $61(19)$ & 0.55 \\
\hline BNP (pg/mL) & $717(349,1542)$ & $990(444,1700)$ & $678(339,1516)$ & 0.045 \\
\hline
\end{tabular}

Notes: Values are presented as median (25, 75 interquartile range) or $\mathrm{N}(\%)$. BMI data was missing in 2 lost follow-up patients. BNP data was missing in 72 (22\%) in followup cases and 5 (10\%) in lost follow-up cases.

Abbreviations: DNR, do-not-resuscitate order; BMI, body mass index; SBP, systolic blood pressure; DBP, diastolic blood pressure; HR, heart rate; COPD, chronic obstructive pulmonary disease; CKD, chronic kidney disease; DM, diabetes mellitus; PCl, percutaneous coronary intervention; CABG, coronary artery bypass graft; ICD, implantable cardioverter defibrillator; CRT-D, cardiac resynchronization therapy with defibrillator; AHF, acute heart failure; ADL, activities of daily living; ACS, acute coronary syndrome; EF, ejection fraction; BUN, blood urea nitrogen; $\mathrm{Cr}$, creatinine; $\mathrm{Na}$, sodium; Hb, hemoglobin; BNP, B-type natriuretic peptide.

Table 3 Association of Early DNR with One-Year Death Among Acute Heart Failure Patients by Forward Stepwise Multivariate Logistic Regression

\begin{tabular}{|l|l|l|}
\hline Factors & Adjusted OR $\mathbf{( 9 5 \% C l )}$ & P value \\
\hline An early DNR & $2.0(1.2-4.0)$ & 0.049 \\
BMI<2 I kg $/ \mathrm{m}^{2}$ & $3.6(1.7-7.8)$ & $0.00 \mathrm{I}$ \\
$\mathrm{ADL}$ dependence & $2.5(1 . \mathrm{I}-5.4)$ & 0.022 \\
$\mathrm{Hb}<10 \mathrm{~g} / \mathrm{dL}$ & $3.7(1.5-7.3)$ & 0.002 \\
\hline
\end{tabular}

Abbreviations: OR, odds ratio; $\mathrm{Cl}$, confidence interval; DNR, do-not-resuscitate; $B M I$, body mass index; ADL, activity of daily living; Hb, hemoglobin.

physicians understand that DNR orders should not interfere with non-CPR procedures, the knowledge that patients have one might lead to a nihilistic approach to treatment. ${ }^{12}$ This would cause physicians not to perform non-CPR procedures and to withdraw aggressive care too early. A previous study showed that having an early DNR order increased the odds of death for intracranial hemorrhage (ICH). ${ }^{13}$ This study showed that hospitals with a higher rate of early DNR orders had lower rates of patient intubation and mechanical ventilation, craniectomy, ventriculostomy, and cerebral angiography for ICH patients. ${ }^{13}$ In another study, patients with a DNR order were less likely to receive guideline-directed heart failure medicine, including ACEi and beta-blocker as well as anticoagulation treatment for atrial fibrillation. ${ }^{5}$ Therefore, a DNR order can theoretically increase mortality by worsening QOC measures. In our hospital, the misuse of a DNR order is prevented by regular lectures (every 3 months) about the definition of a DNR order and by having an order sheet of code status (Figure 1). We reported that, under these circumstances, a DNR order did not affect QOC measures of AHF patients, such as the rate of echocardiography, initiation of beta-blocker and ACEi or ARB for heart failure with reduced $\mathrm{EF}$, and administration of anticoagulant for heart failure with atrial fibrillation. ${ }^{7}$ Therefore, in this study, a worse QOC was less likely to explain the higher rate of oneyear mortality among DNR patients although we could not exclude the possibility that a DNR order leads to withholding unmeasured care which improves prognosis, with a resultant higher rate of one-year mortality.

Another potential explanation for early DNR-associated increase in mortality of heart failure patients is that physicians often consider the prognosis when discussing advance directives, including DNR wishes, with patients and/or families. Heart failure hospitalization by itself is an important predictive factor for death. ${ }^{14}$ Long-term predictive factors for death include advanced age, ${ }^{15,16}$ gender (male), low BMI, ${ }^{15,17,18}$ and New York Heart Association (NYHA) classification. Uremia, anemia, and hyponatremia are also associated with worse mortality for heart failure patients. ${ }^{19}$ The association between DNR orders and higher mortality among heart failure patients could be explained by the fact that the presence of certain poor prognostic factors by themselves may be associated with the will of both physicians and patients to implement a DNR order. In our study, we evaluated factors which are associated with early DNR by multivariate logistic regression analysis as a post hoc analysis (supplementary Table 1). Age $\geq 75$ years, $B M I<21 \mathrm{~kg} / \mathrm{m}^{2}$, dementia, and $\mathrm{Hb}<10 \mathrm{~g} / \mathrm{dL}$ were associated with early DNR order. Even after entering 
these factors for the multivariate logistic regression analysis with the stepwise method, still DNR is associated with oneyear mortality. We need other unmeasured factors for the explanation.

Physicians often consider, in addition to heart failurespecific factors, other common negative prognostic factors, including the advanced stage of other illnesses, such as chronic pulmonary disease, dementia, and malignancy. Frailty is also a risk factor for increased mortality among heart failure patients, ${ }^{19,20}$ and ADL-dependency is associated with a bad one-year prognosis in the general population. ${ }^{21}$ Because elderly patients can present with multiple comorbidities, both physicians and patients often take into account the patient's functional capacity, cognitive function, and other heart failureunrelated disease-related conditions, when requesting a DNR order. Therefore, we postulate that heart failure-unrelated conditions associated with a poor outcome can promote a DNR request from heart failure patients. As a post hoc analysis, we investigated the cause of death: cardiac or non-cardiac, namely, malignancy, stroke, infection, failure to thrive and chronic pulmonary conditions, etc. (supplementary Table 2). We compared it between the early DNR group and the non-DNR group. It showed no significant difference and it did not support the hypothesis that early DNR is associated with an advanced stage of non-cardiac illness, leading to a higher rate of death. Because we did not collect data on whether patients had an advanced stage of non-cardiac illness on admission, we need further study to investigate the association of these factors with early DNRs and mortality.

Advance care planning increased concordance between patients' end of life wishes and treatment received. ${ }^{22}$ It also decreased stress, anxiety, and depression among the bereaved family. ${ }^{22}$ It improved the satisfaction with end of life care, and reduced decisional conflict of end of life care. ${ }^{22}$ Optimal timing of initiating advance care planning has not been investigated yet. However, it can be assumed that the admission day for the acute event is not optimal because there needs to be enough time to discuss prognosis, goal of care, and things to avoid for future care, including code status. According to the Japanese Society of Dying with Dignity, approximately 100,000 people (calculated to be one out of 1200 people) have a living will card which the society issued in Japan. ${ }^{23}$ According to the questionnaire survey conducted by the Japanese ministry of health, labor, and welfare, $59 \%$ of people have already had some idea of life-sustaining treatment at the end of life and would like to make an advance directive. ${ }^{24}$ Health-care providers should ask them whether they have advance directives or advance care planning or would like to discuss it on admission to understand their ideas. The inhospital mortality of acute heart failure was $6 \%$ in our cohort. ${ }^{7}$ Although it is not an ideal time to initiate ACP among patients who have never discussed it in the past, it may be the best time from that point on, because AHF can be a life-threatening condition. Furthermore, discussing code status on admission reportedly decreased invasive procedures before death that cancer ${ }^{25}$ and non-cancer inpatients in an advanced stage would like to avoid. ${ }^{26}$ On admission is not an optimal time to initiate advance care planning; however, we should start advance care planning including code status discussion as soon as possible after admission.

In our study, early DNR was ordered for 80 patients (25\%). DNR was ordered after hospital day 2 for another 22 patients (late DNR order). In one study, only $26 \%$ of heart failure patients requested DNR at the time of enrollment. However, a significant number of patients changed the request over time, and $78 \%$ finally requested DNR. ${ }^{27}$ The prognosis of resuscitated patients with heart failure was not very good. Among patients resuscitated after cardiopulmonary arrest, $36 \%$ survived to hospital discharge and only $9 \%$ had a complete recovery and were able to return home. ${ }^{27}$ Advance care planning, including cardiopulmonary resuscitation preference, is essential and should be kept up-to-date to prevent undesired invasive procedures.

Several limitations of this study should be acknowledged. First, we could not generalize the results because this was a single-center, retrospective study. Second, as much as $12 \%$ of the patients were lost to follow-up. The rate of early DNR, ADL dependency, hemodialysis, and dementia were higher in the lost follow-up group than the complete follow-up group. This may lead to a selection bias. Third, we hypothesized that other conditions affecting the prognosis (such as frailty and advanced stage of dementia) may affect the decision to request a DNR order. A further study should be performed to analyze unmeasured factors associated with a worse prognosis related to early DNR orders among heart failure patients.

\section{Conclusion}

Early DNR order was associated with higher one-year mortality among AHF patients. Further studies will be necessary to investigate unknown factors involved in the decision-making process of requesting a DNR order and in the prognosis of heart failure patients.

\section{Disclosure}

The authors report no conflict of interest in this work. 


\section{References}

1. Beach MC, Morrison RS. The effect of do-not-resuscitate orders on physician decision-making. $J$ Am Geriatr Soc. 2002;50:2057-2061. doi:10.1046/j.1532-5415.2002.50620.x

2. Zingmond DS, Wenger NS. Regional and institutional variation in the initiation of early do-not-resuscitate orders. Arch of Intern Med. 2005;165(15):1705-1712. doi:10.1001/archinte.165.15.1705

3. Wenger NS, Pearson ML, Desmond KA, Brook RH, Kahn KL. Outcomes of patients with do-not-resuscitate orders: toward an understanding of what do-not-resuscitate orders mean and how they affect patients. Arch of Intern Med. 1995;155:2063-2068. doi:10.1001/archinte. 1995.00430190049007

4. Council on Ethical and Judicial Affairs American Medical Association. Guidelines for the appropriate use of do-not-resuscitate orders. JAMA. 1991;265:1868-1871. doi:10.1001/jama.1991.03460140096034

5. Chen JLT, Sosnov J, Lessard D, Goldberg RJ. Impact of do-notresuscitation orders on quality of care performance measures in patients hospitalized with acute heart failure. Am Heart $J$. 2008;156:78-84. doi:10.1016/j.ahj.2008.01.030

6. Bruckel J, Mehta A, Bradley SM, et al. Variation in do-not-resuscitate orders and implications for heart failure risk-adjusted hospital mortality metrics. JACC Heart Fail. 2017;5:743-752. doi:10.1016/j. jchf.2017.07.010

7. Kojima S, Hiraoka E, Arai J, et al. Effect of a do-not-resuscitate order on the quality of care in acute heart failure patients: a singlecenter cohort study. Intern J Gen Med. 2018;11:405-412. doi:10.2147/IJGM.S173253

8. McKee PA, Castelli WP, McNamara PM, Kannel WB. The natural history of congestive heart failure: the Framingham study. $N$ Engl J Med. 1971;285:1441-1446. doi:10.1056/NEJM197112232852601

9. Loertscher L, Reed DA, Bannon MP, Mueller PS. Cardiopulmonary resuscitation and do-not-resuscitate orders: a guide for clinicians. $\mathrm{Am}$ J Med. 2010;123:4-9. doi:10.1016/j.amjmed.2009.05.029

10. Japanese Society of Intensive Care Medicine. Guideline of DNR order in 2016. Available from: http://www.jsicm.org/publication/kan koku_dnar.html. Accessed March 92019.

11. Ferdinando L, Erin Costello M, Puller J, Cooney T, Kottkamp N. TRIAD III: nationwide assessment of living wills and do not resuscitate orders. J Emerg Med. 2012;42:511-520. doi:10.1016/j. jemermed.2011.07.015

12. Hemphill JC. Do-not-resuscitate orders, unintended consequences, and the ripple effect. Crit Care. 2007;11:121. doi:10.1186/cc5687

13. Hemphill JC, Newman J, Zhao S, Johnston SC. Hospital usage of early do-not-resuscitate orders and outcome after intracerebral hemorrhage. Stroke. 2004;35:1130-1134. doi:10.1161/01. STR.0000125858.71051.ca

14. Solomon SD, Dobson J, Pocock S, et al. Influence of Nonfatal hospitalization for heart failure on subsequent mortality in patients with chronic heart failure. Circulation. 2007;116:1482-1487. doi:10.1161/CIRCULATIONAHA.107.696906

International Journal of General Medicine

\section{Publish your work in this journal}

The International Journal of General Medicine is an international, peer-reviewed open-access journal that focuses on general and internal medicine, pathogenesis, epidemiology, diagnosis, monitoring and treatment protocols. The journal is characterized by the rapid reporting of reviews, original research and clinical studies
15. Hamaguchi S, Kinugawa S, Goto D, et al. Predictors of long-term adverse outcomes in elderly patients over 80 Years hospitalized with heart failure. Circ J. 2011;75:2403-2410. doi:10.1253/circj.CJ-11-0267

16. Kinugasa $\mathrm{Y}$, Kato M, Sugihara S, et al. A simple risk score to predict in-hospital death of elderly patients with acute decompensated heart failure-hypoalbuminemia as an additional prognostic factor. Circ J. 2009;73:2276-2281. doi:10.1253/circj.CJ-09-0498

17. Sharma A, Lavie CJ, Borer JS, et al. Meta-analysis of the relation of body mass index to all-cause and cardiovascular mortality and hospitalization in patients with chronic heart failure. Am J Cardiol. 2015;115:1428-1434. doi:10.1016/j.amjcard.2015.02.024

18. Hamaguchi S, Tsuchihashi-Makaya M, Kinugawa S, et al. Body mass index is an independent predictor of long-term outcomes in patients hospitalized with heart failure in Japan- a report from the Japanese Cardiac Registry of Heart Failure in Cardiology (JCARE-CARD). Circ J. 2010;74::2605-2611. doi:10.1253/circj.CJ-10-0599

19. Lee DS, Austin PC, Rouleau JL, Liu PP, Naimark D, Tu JV. Predicting mortality among patients hospitalized for heart failure: derivation and validation of a clinical model. JAMA. 2003;290:2581-2587. doi:10.1001/jama.290.19.2581

20. Wang X, Zhou C, Li Y, Li H, Cao Q, Li F. Prognostic value of frailty for older patients with heart failure: a systematic review and meta-analysis of prospective studies. Biomed Res Int. 2018;2018:9.

21. Yourman LC, Lee SJ, Schonberg MA, Widera EW, Smith AK. Prognostic indices for older adults: a systematic review. JAMA. 2012;307(2):182-192. doi:10.1001/jama.2011.1966

22. Weathers E, O'Caoimh R, Cornally N, et al. Advance care planning: a systematic review of randomised controlled trials conducted with older adults. Maturitas. 2016;91:101-109. doi:10.1016/j.maturitas.2016.06.016

23. Japanese Society of Dyning with Dignity. Available from: https:// songenshi-kyokai.or.jp/.Accessed June 4, 2020

24. Survey of the general public's attitudes toward end of life treatment. Reported in 2017 by Ministry of Health, Labour and Welfare (in Japanese). Available from: https://www.mhlw.go.jp/toukei/list/dl/sai syuiryo_a_h29.pdf. Accessed January 29, 2020.

25. Caissie A, Kevork N, Hannon B, Le LW, Zimmermann C. Timing of code status documentation and end-of-life outcomes in patients admitted to an oncology ward. Support Care Cancer. 2014;22:375-381. doi:10.1007/s00520-013-1983-4

26. Sasaki A, Hiraoka E, Homma Y, et al. Association of code status discussion with invasive procedures among advanced-stage cancer and noncancer patients. Int $J$ Gen Med. 2017;10:207-214. doi:10.2147/IJGM.S136921

27. Shannon MD, KM Swetz, MM Redfield, PS Mueller, VL Roger. Resuscitation preferences in community patients with heart failure. Circ Cardiovasc Qual Outcomes. 2014;7:353-359. doi:10.1161/ CIRCOUTCOMES.113.000759 system, which is all easy to use. Visit http://www.dovepress.com/ testimonials.php to read real quotes from published authors.

\section{Dovepress}

(n)

